\title{
Alternativas de ensino em tempo de pandemia
} Teaching alternatives in pandemic times

\section{Alternativas de enseñanza em tempo de pandemia}

Recebido: 30/07/2020 | Revisado: 04/08/2020 | Aceito: 19/08/2020 | Publicado: 23/08/2020

Douglas dos Santos Silva

ORCID: https://orcid.org/0000-0001-8726-777므

Universidade Estadual do Piauí, Brasil

E-mail: professordouglassantos@gmail.com

Leane Amaral Paz Andrade

ORCID: https://orcid.org/0000-0002-7210-5050

Universidade Estadual do Piauí, Brasil

E-mail: leane.amaral@hotmail.com

Silvana Maria Pantoja dos Santos

ORCID: https://orcid.org/0000-0002-1107-1336

Universidade Estadual do Piauí, Brasil

E-mail: silvanapantoja3@gmail.com

\section{Resumo}

O objetivo desse artigo é compreender as novas alternativas de ensino-aprendizagem por meio de plataformas digitais Google Classroom e Google Meet no Instituto Federal do Maranhão de Coelho Neto aos alunos de $3^{\circ}$ ano de Ensino Médio durante o período da pandemia no Brasil. Elas estão desempenhando uma importante função pedagógica de inovação aos estudantes que sentiram os impactos do fechamento das instituições de ensino, principalmente, os oriundos da esfera pública que foram os mais prejudicados em se tratando de área tecnológica. Para tanto, usaremos como aporte teórico as reflexões de Moore para quem o diálogo numa relação educacional é dirigido para o progresso da compreensão por parte do estudante; Pereira que entende o ambiente virtual de aprendizagem como uma opção para mediar o ensino-aprendizagem; Mendes e Lemes que observam alguns vácuos entre as aulas presenciais e as propostas pedagógicas na área da tecnologia.

Palavras-chave: Ensino; Google classroom; Pandemia; Língua Portuguesa. 


\begin{abstract}
The objective of this article is to understand the new teaching-learning alternatives through digital platforms Google Classroom and Google Meet at the Federal Institute of Maranhão de Coelho Neto to students of the 3rd year of high School during the pandemic period in Brazil. They are playing an important pedagogical role in innovation for students who have felt the impacts of the closure of educational institutions, especially those from the public sphere who were the most affected when it comes to the technological area. To this end, we will use as theoretical input as Moore's reflections for whom the dialogue in an educational relationship is directed towards the progress of understanding by the student; Pereira who understands the virtual learning environment as an option to mediate teaching and learning; Mendes and Lemes who observe some gaps between the face-to-face classes and the pedagogical proposals in the area of technology.
\end{abstract}

Keywords: Teaching; Google classroom; Pandemia; Portuguese language.

\title{
Resumen
}

Este trabajo tiene por objetivo comprender las nuevas alternativas de enseñanza- aprendizaje por medio de las plataformas digitales Google Classroom y Google Meet en el Instituto Federal del Maranhão de Coelho Neto a los alumnos del $3^{\circ}$ año de la enseñanza media durante el periodo de la pandemia en el Brasil. Ellas están desempeñando una función pedagógica de innovación importante a los estudiantes que sufren con el impacto del cierre de las instituciones de enseñanza, especialmente, los que proviene del sistema público como los más perjudicados en el área tecnológica. Por lo tanto, se usa como aporte teórico las reflexiones de Moore a quien el diálogo en una relación educacional se direcciona al progreso de comprensión por parte del estudiante; Pereira que tiene el ambiente virtual de aprendizaje como una opción para mediar la enseñanza-aprendizaje; Mendes y Lemos que observan algunos huecos entre las clases presenciales y las propuestas pedagógicas en el área tecnológica.

Palabras clave: Enseñanza; Google classroom; Pandemia; Lengua portuguesa.

\section{Introdução}

Os ambientes de educação remotos vêm aumentando em razão da pandemia do COVID-19 que interrompeu as aulas presenciais em todas as instituições de ensino no país. 
Fato que possibilitou o cumprimento das aulas serem organizadas através de plataformas digitais como o Google Classroom e salas de reunião por meio do Google Meet.

Nesse sentido, o Instituto Federal do Maranhão (IFMA) da cidade de Coelho Neto decidiu construir ações pedagógicas de ensino-aprendizagem por meio de aulas não presenciais para alunos de Educação Profissional Técnica de Nível Médio do $3^{\circ}$ ano a fim de reorganizar o Calendário Escolar em função de enfrentar os desafios decorrentes do Novo Coronavírus. Assim sendo, o corpo escolar se fundamentou na Portaria $\mathrm{N}^{\mathrm{o}} 2.618$ de 12 de Junho de 2020 que trata da substituição das aulas presenciais por aulas em meios digitais no tempo em que durar as circunstâncias da pandemia do COVID-19. Dessa forma, como meio alternativo de interações entre professores e alunos ficou decidida a utilização das plataformas supracitadas, visto que são ferramentas apropriadas a esse processo de educação remota.

Por essa razão, a escola deve construir novas ações pedagógicas para enfrentamento da pandemia. Dessa forma, para (Moran, 2013), é necessário que a escola transforme o universo educacional em espaços motivadores e significativos ao aprendizado para que os estudantes se tornem autônomos na construção dos conhecimentos. As instituições de ensino devem promover a busca do aprendizado, mesmo em tempos de crise sanitária mundial. É importante que os estudantes tenham a oportunidade de desenvolverem o pensamento crítico e busca pela pesquisa para se tornarem sujeitos da sua formação humanística. Acrescentamos ainda (Moore, 1993) que discute a ideia de que o ensino à distância pode ser um mecanismo facilitado por meios impressos e eletrônicos promovendo uma relação interativa entre docente e discente.

Com isso, vemos que os espaços virtuais se tornaram um dos caminhos necessários para a continuação da educação no Brasil. As aulas presenciais foram interrompidas abruptamente por meses prejudicando milhares de estudantes, principalmente, aqueles provenientes da rede pública. Assim, de acordo com Mendes e Lemes (1999), na escola ainda existem alguns problemas entre as aulas presenciais e as medidas pedagógicas com relação à tecnologia trabalhada pelos professores. Entretanto, a escola precisa se readaptar a essas inovações de modo que proporcione aos docentes novas estratégias de ensino utilizando o espaço cibernético.

Enfatizamos que existem maneiras relevantes para otimizar o trabalho do educador no desenvolvimento de ensino das línguas nas escolas através da tecnologia. O estudo da Língua Portuguesa no Ensino Médio, por exemplo, pode ser mediada com inovações tecnológicas que antes eram negligenciadas pelos professores ou até desconhecidas por eles. Dessa maneira, a 
implementação de suportes tecnológicos como o Google Sala de Aula introduziu características de elaboração de atividades, bem como avaliativas aos educadores como uma complementação às aulas presenciais e, sobretudo, abordagem do conhecimento científico via plataformas digitais e arquivamento nas nuvens. Por isso, o conhecimento de gramática, literatura e produção textual se ampliou em virtude de capacidades diversificadas de aprendizado.

Em vista disso, os sistemas escolares analisam com os profissionais de educação as melhores estratégias de ensino como forma de utilizar atividades síncronas e assíncronas tornando as aulas híbridas e proporcionando o ensino completo aos estudantes com e sem acesso à internet. Além disso, as instituições precisam garantir o auxílio tecnológico a todos os alunos, inclusive, aos que não têm disponibilidade dessa tecnologia. Por isso, cada docente precisaria organizar seu material didático a partir de materiais impressos, livros digitais, PDF, pen drive ou outros meios a fim de contemplar todos.

Portanto, este trabalho está organizado da seguinte maneira: na seção dois o Google Classroom e o Google Meet são descritos; na seção três o ensino da língua através de aulas não presenciais e na seção quatro são apresentadas as considerações finais para demonstrar a importância desses mecanismos para o ensino-aprendizagem nas escolas.

\section{Google Classroom e Google Meet}

A pesquisa realizada foi de natureza qualitativa, fundamentada em Pereira (et al, 2018), que a define como "[...] uma metodologia de estudo de fenômenos individuais ou, processos sociais". Dessa forma, nossa pesquisa trabalhou o lócus investigativo do Instituto Federal de Ciência e Tecnologia do Maranhão no campus da cidade de Coelho Neto - MA a partir de práticas de ensino remoto nos meses de Junho e Julho de 2020 com professores de língua portuguesa cuja finalidade era trabalhar os conteúdos parados desde o mês de março do corrente ano em razão da suspensão das atividades presenciais em todo o país.

Nesse sentido, sabe-se que as salas de aulas presenciais durante o período de isolamento social ficaram inativas. Entretanto, as salas de aula virtuais surgiram como alternativa às instituições de ensino a fim de evitar a perda do ano letivo. Nesse contexto, os educadores encontraram na plataforma do Google os suportes tecnológicos para continuarem os trabalhos pedagógicos conforme a Base Nacional Comum Curricular que enfatiza a 
competência de se valorizar e utilizar os conhecimentos historicamente construídos sobre o mundo físico, social, cultural e digital para entender e explicar a realidade (Brasil, 2016).

O Google Classroom é um sistema que gerencia os conteúdos para escolas e profissionais da educação como forma de criar atividades de ensino, bem como formas diversificadas de avaliações de acordo com a turma selecionada. É uma plataforma existente desde o ano de 2014 e que poucos docentes utilizavam como ferramenta educacional. Contudo, ela se tornou um dos principais instrumentos de atividades acadêmicas de assessoramento aos professores nesse tempo de surto sanitário no Brasil. E o Instituto Federal do Maranhão de Coelho Neto resolveu formar os servidores e iniciar o trabalho piloto a partir desse gerenciador de conteúdos, uma vez que implantou o $G$ suíte for education e com disponibilidade para os campi da instituição. Assim, o também conhecido Google Sala de Aula tem oferecido possibilidades de comunicação, interação e produção de conteúdos favoráveis ao processo de ensino-aprendizagem de modo que o uso do Classroom também pode beneficiar a instituição de ensino quando passa a ser o centro para a exploração de conteúdos de sala de aula e atividades destinadas aos alunos (Iftakhar, 2016).

Esse é um ambiente virtual em que o docente organiza as turmas por séries ou cursos integrados (administração, informática ou automação), arquiva as atividades e orienta os trabalhos. Além disso, o orientador acompanha o desenvolvimento intelectual do aluno de maneira efetiva acrescentando comentários, se necessário, e notas avaliativas. Toda respectiva atividade lançada no sistema, o estudante recebe uma notificação no e-mail para participar da proposta e devolver ao educador. O acesso aos materiais e conteúdos disponibilizados na plataforma são exclusivos dos servidores e estudantes devidamente cadastrados e vinculados ao domínio da instituição. Uma maneira segura contra possíveis invasores de sistemas operacionais como também uma forma de promover a ordenação dos assuntos respectivos à escola.

A plataforma também direciona os materiais a um link com o Google Drive a fim de arquivamento nas nuvens. Desse modo, a partir do momento em que o professor criar uma nova turma, simultaneamente no Google Drive é formada uma pasta para a sala e possíveis incorporações de exercícios para serem arquivados. Dependendo da necessidade, o professor pode excluir as ações concluídas, mas também adicionar ou reexaminar a qualquer instante no sistema.

Esse espaço cibernético é tão importante que o professor pode elaborar documentos, inserir vídeos do Youtube, câmera do celular ou notebook, apresentações de Power Point, 
PDF e outros. Todos esses registros ficam ao dispor do aluno a fim de ler, estudar e praticar as atividades. Em seguida, com a devolução da atividade ou da avaliação, o docente pode disponibilizar uma nota a ser visualizada pelo aluno de forma imediata ou somente ao final da revisão. Também é gerada uma planilha para o controle acadêmico de todos os participantes.

Assim sendo, todos os alunos recebem as informações acerca da proposta indicada com a possibilidade de prazos estipulados reduzindo a probabilidade de descuido quanto ao tempo de entrega.

Outra ação pertinente do Google Classroom é a promoção do contato entre o professor e aluno por meio de uma sala de reunião síncrona onde o aluno tira as dúvidas se conectando com o professor de forma interativa. Por meio desses exemplos de interação, podemos dimensionar o uso dessa plataforma de acordo com o que é mencionado pelos autores (Garcião, Baião, Correia \& Silva, 2015) que ressaltam a importância e o desenvolvimento dessas tecnologias quanto ao aprendizado por parte dos docentes de uma instituição. E isso facilita o relacionamento direto na comunicação entre o educador e o aluno evitando que questionamentos passem despercebidos.

De acordo com (Rochelle, 2016), o G Suite for Education se tornou o canal mais viável oferecido pelo Google às instituições de ensino pois permitiu que os servidores pudessem se reunir de forma online, mas também proporcionar à comunidade escolar as aulas de forma remota. Nessa perspectiva, o Google Meet se tornou a solução ao IFMA. Ele é um dispositivo gerenciado pelo computador ou outro equipamento móvel de forma que possibilita a conectividade entre o profissional da instituição e alunos no sistema home Office. Para (Santos, 2017), essa plataforma é gratuita para as escolas que dispõem do sistema e se tornou um dos melhores recursos para Google desenvolver na área de educação. E, isso, favorece o professor que pode selecionar o material de estudo ou pesquisa e dentro de sua residência organizar a reunião e enviar um link pelas redes sociais ou e-mail aos convidados.

No entanto, pessoas que não fizerem parte do grupo escolar ou estiverem fora do domínio da instituição necessitam de uma aprovação do organizador da sala para que possam participar da conferência, logo, as vídeo-chamadas são criptografadas com medidas de segurança contra possíveis invasores, mas também resguardam os membros da reunião de prováveis vazamentos.

Essa ferramenta é utilizada pelos professores de Coelho Neto (MA) como um viés para atender as necessidades da escola permitindo que os mesmos possam interagir com os estudantes de forma síncrona, além de que o aplicativo é um importante mecanismo de 
realização de reuniões de videoconferência com capacidade até 250 participantes ao mesmo tempo.

A vantagem do Meet pelo computador é que não necessita de instalação de aplicativo e o acesso à sala de aula virtual é realizado de modo direto com Google Chrome. O professor ainda pode criar uma reunião e deixar agendada por meio do Google Agenda e adicionar o email individual do estudante ou copiar um link para disponibilizar nas redes sociais como WhatsApp ou Instagran facilitando a rápida comunicação entre todos. O sistema, então, prepara a sala para ser acessada pelos integrantes, no entanto, o aluno que não receber o convite, somente participará após a aprovação de outro membro da reunião. Nos aparelhos móveis que possuem o sistema Android não é necessária a instalação do G Suite, mas se o aluno não conseguir o acesso recomenda-se baixar o App Google Meet pelo Play Store e no iOS fazendo download do mesmo programa. E, assim, a conexão vai fluir normalmente e o participante pode acompanhar a aula por meio do celular sem sair de casa evitando se arriscar ao vírus do COVID-19.

Uma das vantagens de se trabalhar nessa plataforma é a demanda de um espaço virtual seguro e eficaz para o rendimento desejado pelas escolas. Ela é uma ferramenta simples, acesso fácil e sem complexidades na sua utilização. Um exemplo disso é o compartilhamento de telas do Power Point, Word, PDF ou outras janelas do computador com os participantes da sala para apresentar as atividades, documentos, tarefas, vídeos ou interagir via chat com mensagens para os integrantes. Acrescentamos ainda a capacidade que o sistema possui de arquivamento dos dados na nuvem. O Meet não precisa de aplicativos instalados no computador, pois, o membro da sala depende apenas da conexão da internet sem a necessidade de equipamento próprio para a reunião. E isso traz mais mobilidade para o professor gerenciar suas atividades com os alunos de maneira remota. Além de tudo, caso o computador tenha qualquer problema durante a exposição, o participante tem a possibilidade de retornar à sala por outro equipamento como notebook ou mesmo um celular.

Outro ponto positivo é a acessibilidade da plataforma. O conteúdo da aula pode ficar disponível aos estudantes que por alguma eventualidade perderam a reunião. Dessa forma, o professor grava o encontro e torna-o acessível a todos para que possam assistir quando desejarem. Nos celulares Android, é possível também baixar o App Meet para acompanhar as aulas sem a necessidade de um computador ou tablete. Para os alunos, isso facilita o acompanhamento das aulas em tempo real favorecendo o aprendizado remoto, auxiliando o estudante com possíveis dúvidas acerca do assunto e otimizando o trabalho do professor, 
logo, todos podem interagir pelo chat ou ligando o microfone para falar. Em (Schiehl \& Gasparini, 2016) também são mencionados outros aplicativos importantes que compõem o $G$ Suite for Education como forma de complementação à plataforma através de salvamento de dados automaticamente, uma historicidade dos arquivos compartilhados e a possibilidade de comentários.

Essas funcionalidades são importantes nesse contexto de isolamento social, visto que as instituições de ensino têm a oportunidade de transmitir as aulas para um grupo de estudantes de forma satisfatória priorizando o ensino-aprendizagem. Os professores não precisam ser Youtuber ou terem qualificação em área de tecnologia para apresentarem as aulas. Os recursos disponíveis no Meet são fáceis para a utilização e contribuem para uma educação favorável através do espaço virtual reduzindo o distanciamento das aulas presenciais.

Por isso, é importante que o docente busque o aprimoramento das ferramentas do Google Classroom e Google Meet para que possa contribuir de forma eficaz na formação dos estudantes de Educação Básica. Logo, o uso da tecnologia vai ser uma modalidade presente na vida de todos mesmo com as aulas presenciais normalizadas.

\section{Ensino da Língua Portuguesa Através de Aulas Não Presenciais}

Os ambientes virtuais de aprendizagem é uma realidade no Brasil há muito tempo. Esses espaços foram criados para a organização de conteúdos e proporcionar a interação entre os envolvidos no sistema educativo. Nesses ambientes, a eficiência do processo educacional depende do compromisso do aluno, do trabalho pedagógico, recursos disponíveis e, sobretudo, a qualidade dos profissionais vinculados.

Por essa razão, existem pesquisadores que defendem a utilização de ambientes virtuais de aprendizagem no contexto escolar. Segundo (Pereira 2007), o Ambiente Virtual de Aprendizagem (AVA) consiste em uma opção de mídia que está sendo utilizada para mediar o processo de ensino-aprendizagem à distância. Ele considera que a qualidade dos atores envolvidos nesse processo pedagógico deve ser uma das características para utilização dessa ferramenta. E ainda tem uma função de integrar mídias distintas em ambientes virtuais a partir de elementos como imagem, som e vídeos integrados num mesmo espaço. Para (Solange, 2017), num mundo em profunda transformação a educação precisa ser muito mais flexível, híbrida, digital, ativa e diversificada. 
Nesse sentido, no período de pandemia no país, as escolas foram surpreendidas com o avanço da doença que provocou a suspensão imediata das aulas presenciais. Dessa forma, a criação de Ambientes Virtuais de Aprendizagem via Educação a Distância (EAD) ficou impossibilitada, principalmente, às instituições de ensino público, pois, o tempo para a adaptação e qualificação dos profissionais de educação era limitado. Ainda seriam necessárias mudanças no Projeto Político Pedagógico que gerariam novas discussões na proposta educacional das escolas. E isso atrasaria o planejamento de estratégias de continuação das aulas presenciais iniciadas.

Por essa razão, o Instituto Federal do Maranhão de Coelho Neto não trabalhou a Educação a Distância e seguiu as orientações gerais da reitoria para trabalhar de maneira remota até a publicação oficial da Portaria No 2.618 de 12 de Junho de 2020 que estabeleceu as Diretrizes para atividades não presenciais.

Estabelecer as Diretrizes para a realização de Atividades Pedagógicas não Presenciais em cursos presenciais de Educação Profissional Técnica de Nível Médio, de Graduação e Pós-Graducação do IFMA, para a reorganização do Calendário Escolar 2020, em função da excepcionalidade de enfrentamento da Pandemia do Novo Coronavírus (COVID-19), conforme Anexo I desta Portaria (Brasil, 2020, Art. 1).

Nesse contexto, O IFMA decidiu realizar um alinhamento com o Projeto Pedagógico Institucional - PPI que aponta para uma Educação Integral em que cada campus tem autonomia, flexibilidade, garantia de uma educação inclusiva e de qualidade, assim como a preservação da saúde física e emocional da comunidade escolar. Desse modo, entendemos que as diretrizes criadas oferecem às instituições de ensino federal instrumentos que impeçam os estudantes de retrocederem o conhecimento escolar. Com isso, as escolas podem planejar as atividades não presenciais como forma de corrigir e equilibrar o ano letivo de 2020 e reduzir a reposição das aulas presenciais.

Essas atividades equivalem ao trabalho realizado nas salas convencionais de modo que o professor reorganize os planos de ensino, metodologias e mediações assertivas de aprendizagem que envolva as tecnologias de informação. Para isso, é necessário que a comunicação entre os atores seja efetiva por canais interativos. Assim, as aulas virtuais podem ser realizadas de forma síncrona, quando professores e alunos interagem ao mesmo tempo ou de maneira assíncrona, quando a interação é realizada em momentos distintos por meio de registros em plataformas virtuais como Google Classroom ou outros meios. 
As atividades síncronas são realizadas através da ferramenta Google Meet disponibilizadas a todos os alunos e professores que são do mesmo domínio do IFMA trazendo mobilidade e segurança aos participantes da sala. As atividades assíncronas são desenvolvidas paralelamente às atividades simultâneas, uma vez que cada professor tem autonomia para criar seus materiais de ensino como textos impressos, PDF, Power Point e outros recursos a fim de favorecer estudantes com ou sem acesso à internet proporcionando uma educação igualitária e de qualidade. Por isso, como medida de implementação dessas ferramentas no trabalho remoto dos docentes, a instituição ofereceu cursos de formação do Google Meet e Google Classroom a cada servidor oportunizando qualificações necessárias para o desenvolvimento das atividades de forma assertiva.

Nessa perspectiva, o ensino da língua portuguesa é trabalhado a partir de aulas síncronas em que permitem aos atores discutirem regras da língua, vídeos, exercícios comentados, interação por microfone ou câmera ligada, chats e outras estratégias em tempo real. Alternativas em que os participantes constroem uma comunicação construtiva. Para (Moore, 1993), um diálogo deve ser intencional, construtivo e valorizado por cada parte e que o mesmo deve ser direcionado para o aperfeiçoamento da compreensão do estudante.

Segundo Moore, a educação deve ser um processo social constante e que ocorre de forma construtiva e dialogada para que haja uma relação interativa entre os agentes da comunicação na sala de aula. E o processo não pode acontecer isoladamente, mas na ligação dos professores e alunos de modo que o diálogo se torne a essência para o desenvolvimento da aprendizagem dos estudantes desde o conhecimento do ambiente virtual até a produção nele.

Para (Horn \& Staker, 2015), há inovações mais pontuais e profundas que modificam a educação formal, capazes de proporcionar novas configurações híbridas, dinâmicas e integradoras. Por isso, o ensino-aprendizagem de língua portuguesa em tempo de pandemia do COVID-19 é um desafio para educadores da área. As instituições de ensino suspenderam as aulas presenciais e o trabalho remoto tornou-se uma alternativa de complementação do ensino aos estudantes de escolas públicas. Entretanto, dificuldades nesse processo ocorrem permanentemente. A conexão através de dispositivos eletrônicos é imprescindível aos alunos, a participação deles na sala virtual e a frequência em atividades assíncronas como Google Classroom é fundamental para que o professor possa mensurar o nível de aprendizado de todos os alunos. Esses fatores deixam claro o abismo tecnológico existente aos estudantes 
oriundos da rede pública impedindo que a escola cumpra o papel de educar de maneira inclusiva.

Assim, medidas podem surgir a partir de estratégias criadas por professores e equipe pedagógica, assim como do Governo Federal para minimizar as desigualdades educacionais no país. Em primeira análise, investir na estrutura de conexão aos estudantes sem qualquer tipo de acesso por meio de bolsa estudantil que contribua para implementação de wi-fi na casa destes. A escola também deve planejar com professores aulas atrativas e fazer investimentos apropriados em inovação tecnológica como laboratórios de salas virtuais com a opção de o professor gravar as aulas de forma profissional com som, iluminação e padronização de vídeos para os alunos. Além de elaborar métodos assertivos de uso da ferramenta Google Classroom como a proposta de gamificação para estudo de língua portuguesa e literatura.

Para estudar modernismo, por exemplo, o professor pode elaborar no Classroom dinâmicas de jogo abordando o contexto histórico, as características literárias e os representantes desse movimento para o Brasil. Desse modo, a literatura moderna pode ser compreendida de maneira dinâmica sendo associada às aulas síncronas pelo Google Meet melhorando o aprendizado, estimulando ações e comportamentos dentro da plataforma, como também de atividades a serem realizadas fora do contexto virtual.

A mesma estratégia de ensino pode acontecer também para o estudo dos elementos básicos de comunicação e funções de linguagem. No Google formulário, é desenvolvida uma atividade para compreender a linguagem em diferentes funções. $\mathrm{O}$ jogo convida o estudante a idealizar um ambiente comunicativo dentro de uma empresa. A cada nova etapa é apresentada outra situação comunicativa em que o mesmo tem somente dois trajetos. O dono da empresa promove reuniões e destaca ações que cada departamento deve realizar contextualizando diferentes funções comunicativas. Para isso, é preciso que o conteúdo ministrado na sala virtual do Meet e o material complementar impresso ou em PDF seja compartilhado entre todos os envolvidos.

Técnicas pedagógicas de ensino de língua portuguesa como a gamificação são construídas nesse cenário de isolamento social em que o aluno se encontra desmotivado em casa e sem a presença física do professor para facilitar o aprendizado. Além de tudo, isso favorece os estudantes que possuem habilidades digitais como os estudantes do Instituto Federal do Maranhão de Coelho Neto que estão inseridos numa instituição que valoriza o uso de tecnologias. As atividades no formato de gamificação também favorece os estudantes com 
menos intimidade em ferramentas digitais e provoca o aprendizado de forma lúdica com etapas a serem conquistadas, premiações e outras motivações típicas de um jogo interativo.

De acordo com (Bergmann \& Sams, 2016), a sala de aula deve buscar uma metodologia ativa de aprendizagem em que os alunos reconheçam a competência de seu próprio conhecimento. Por isso, é importante que o docente apresente um ensino personalizado de modo que proporcione estratégias de aprendizagem em que o estudante deixe de decorar os assuntos de sala de aula e passe a assimilar as atividades de forma ativa. Para (Moran, 2015), as metodologias precisam acompanhar os objetivos pretendidos. Desse modo, ele entende que os professores necessitam de métodos inovadores em que os alunos sejam estimulados a tomada de decisões e avaliação de resultados.

A educação nesse momento de isolamento social precisa se adaptar às novas tecnologias, por esse motivo, (Gomez, 2015) enfatiza a ideia de que é necessário a preparação dos cidadãos não somente para ler e escrever nas plataformas multimídias, mas para que se envolvam com esse mundo. O contexto tecnológico atual proporciona mudanças nas metodologias de ensino. É preciso que o professor utilize sua criatividade e experimente outras possibilidades pedagógicas previamente organizadas para atividades presenciais ou não presenciais.

Essas experiências educativas podem ser feitas pelos estudantes sem sair de casa propiciando a eles competências para o juízo crítico, produtivo e científico na área de língua portuguesa. Assim, elas servem também como complementação às aulas presenciais após o retorno delas ou concomitantemente a essas atividades. Somado a isso, o professor deve disponibilizar outras atividades síncronas ou assíncronas como vídeoaulas, arquivos digitais de aula como Podcast, apresentações em Power Point, livros em formato digital, e-book, textos para leitura como artigos científicos, resenhas, resumos, vídeos do Youtube, propostas de redação no Classroom ou Google formulário, grupos de estudo dirigido e atividades avaliativas através de questionários eletrônicos e atividades off-line. Acrescentamos ainda que as atividades educacionais não trabalhadas pelos meios digitais têm a possibilidade de serem desenvolvidas por instrumentos impressos como material apostilado, relação de exercícios e o livro didático adotado na escola.

Percebemos, então, possibilidades diversificadas de ensino da língua portuguesa nas áreas de gramática, literatura e redação que asseguram o ensino-aprendizagem aos estudantes evitando perdas significativas quanto às atividades pedagógicas no ano letivo corrente. 


\section{Considerações Finais}

O desenvolvimento do presente texto possibilitou uma análise dos instrumentos de trabalhos remotos no Ambiente Virtual de Aprendizagem durante o período de isolamento social em razão do COVID-19 e que provocou a suspensão das aulas presenciais no Instituto Federal do Maranhão da cidade de Coelho Neto. Com isso, esse estudo trouxe contribuições para profissionais da educação trabalharem conteúdos didáticos através de plataformas digitais como Google Classroom e Google Meet. Além disso, apresentou outros recursos didáticos de aulas online e atividades assíncronas que proporcionem o ensino-aprendizagem eficiente e igualitário aos alunos com e sem acesso à internet.

Assim, mesmo diante de dificuldades de acesso à internet e pouco conhecimento acerca das ferramentas, muitos professores criaram projetos de ensino remoto e trabalham semanalmente os conteúdos com uma parte dos alunos de cada curso de administração ou informática. Os docentes que possuíam algum conhecimento de ferramentas virtuais ofereciam aulas por meio do Meet apresentando os slides via Power Point e gravando as mesmas para disponibilizar no e-mail dos estudantes, principalmente, àqueles que estavam indisponíveis no momento da aula por ausência de conexão.

Embora as aulas presenciais estivessem suspensas, um projeto criado pelo professor Diego Orsano de Matemática trouxe a participação de inúmeros colegas de outras áreas para trabalhar aulas preparatórias para o vestibular. Desse modo, professores de Matemática, Língua Portuguesa, Biologia, Química, Física, Arte, Filosofia, Sociologia, História, Inglês, Geografia ofereciam aos estudantes aulas de 120 minutos com questões trabalhadas em vestibulares diversos em todo o país. As aulas eram realizadas às terças e quintas-feiras entre 15:30 às 18:00. O projeto foi chamado de ENEM CONNECT e era apresentado pela plataforma Google Meet em tempo real. Contudo, as aulas eram gravadas e disponibilizadas aos alunos que estavam ausentes. A participação e interação dos alunos foi essencial para a permanência do projeto durante os meses de inatividade das aulas presenciais. E também contribuiu para o desenvolvimento de habilidades nessas ferramentas ao professor.

De um modo geral, os docentes demonstraram interesse em trabalhar as aulas utilizando as ferramentas digitais, sobretudo, professores de Língua Portuguesa que continuaram os trabalhos de redação voltadas ao Enem. Nesse sentido, as propostas de redação eram enviadas na plataforma Google Classroom e alunos diante de um código 
entravam na sala destinada a turma e redigiam os textos deixando-os arquivados no sistema. $\mathrm{O}$ professor, então, fazia a correção e dava o feedback utilizando esse espaço cibernético.

Outro impacto positivo das aulas usando o Classroom foi a criação de projetos de pesquisa utilizando a gamificação de atividades de língua portuguesa e literatura. Alunos de informática perceberam como a inovação tecnológica pode melhorar a compreensão de conteúdos como função da linguagem, concordância verbal, o contexto do Modernismo entre outros diversos assuntos e, assim, transformar as atividades linguísticas em situações de storytelling por meio de jogos ou situações criadas no Google Formulário para favorecer o aprendizado.

Diante do discurso dos alunos envolvidos nos projetos de ensino, no ENEM CONNECT e uso de gamificação ficou evidente que os objetivos foram alcançados possibilitando a outros profissionais da área mais pesquisas acerca dessas ações, assim como desenvolver outras estratégias didáticas que contribuam para a educação.

Para (Valente, 2014), a sala de aula precisa ter uma modalidade de ensino híbrido em que haja a combinação da educação formal com ensino on-line de forma que uma parcela de conteúdo das aulas aconteçam na internet e a outra na sala de aula. Assim, verificamos que o isolamento social proporcionou alternativas pedagógicas para se trabalhar de maneira remota, mas também para trabalhos futuros quando as aulas presenciais retornarem. Precisamos reconhecer que a educação é inovadora e diversificada. E o professor deve rever suas estratégias de ensino porque o uso das tecnologias veio para contribuir à educação tradicional.

Constatamos, portanto, que o ensino de língua portuguesa nesse período de isolamento social é possível. O professor precisa de motivação para aprender esses recursos disponíveis em tutoriais no Youtube ou outros meios de aprendizagem. É necessário que a qualificação para o uso dessas ferramentas seja uma busca constante a fim de ter habilidades necessárias para um bom trabalho virtual, como também oportunizar os alunos a continuarem o processo de aprendizagem em tempos de pandemia.

Portanto, novas discussões devem ser abordadas pelos pesquisadores a fim de encontrarmos alternativas de ensino nesse período de pandemia buscando investigar por meio de pesquisas futuras estratégias de metodologias ativas como o ensino híbrido e a sala de aula invertida para atualizar a prática docente durante o ensino remoto. 


\section{Referências}

Bergmann, J., \& Sams, A. (2016). Sala de aula invertida: uma metodologia ativa de aprendizagem. Tradução Afonso Celso da Cunha Serra. - Rio de Janeiro LTC.

Brasil. (2020). Ministério da Educação. Instituto Federal de Educação, Ciência e Tecnologia do Maranhão. Reitoria. Portaria No 2.618 de 12 de Junho. Estabelece as Diretrizes para a realização de Atividades Pedagógicas não Presenciais em cursos presenciais de Educação Profissional Técnica de Nível Médio, de Graduação e Pós-Graduação do IFMA, para a reorganização do Calendário Escolar 2020, em função da excepcionalidade de enfrentamento da Pandemia do Novo Coronavírus (COVID-19).

Brasil. (2016). Ministério da Educação. Secretaria da Educação Básica. Base Nacional Comum Curricular. Brasília, DF, 2016. Recuperado de < http://basenacionalcomum.mec.gov.br/\#/site/inicio>

Garcião, A. O., Baião, E. R., Corrêa, L. R., Silva, R. A. (2015). Ferramentas Google: Potencialidades De Formação Continuada Para Docentes Com A Formação De Competências De Domínio Tecnológico. III Simpósio Internacional de Inovação em Educação. Recuperado de <http://www.lantec.fe.unicamp.br/inova2015/images/trabalhos /artigos/T5.pdf>

Horn, M. B., \& Staker, H. (2015). Blended usando a inovação disruptiva para aprimorar a educação. Porto Alegre: Penso.

Iftakhar, S. (2016). Google Classroom: what Works and how? Journal of Education and Social Sciences, 3. Recuperado de http://jesoc.com/wp-content/uploads/2016/03/KC3_35.pdf

Gómez, A. I. Perez. (2015). Educação na Era Digital: a escola educativa. Tradução Marisa Guedes, Porto Alegre: Penso, 192 p.

Mendes, S. M. C., \& Leme, M. E. G. (2014). A mediação pedagógica: formação docente para a educação inclusiva frente às novas tecnologias. Brazilian Journal of Technology, 
Communication, and Cogntive Science, 2(2), 1-12. Recuperado de http://www. anais.tecccog.net/index.php/anais/article/view/11.

Moore, M. G., \& Kearsley, G. (2013). Educação a distância: sistemas de aprendizagem online. São Paulo: Cengage Learning.

Moore, M. G. (1993). Theory of transactional distance. In: Keegan, D. London: Routledge, p.03-38. Traduzido por Wilson Azevedo. In: Revista de Aprendizagem Aberta e a Distância, São Paulo, Agosto, 2002.

Moran, J. M. (2015). Mudando a educação com metodologias ativas. Coleção Mídias Contemporâneas. Convergências Midiáticas, Educação e Cidadania: aproximações jovens. Vol. II. Foca Foto-PROEX/UEPG.

Pereira., et al.(organizadores). (2007). AVA: Ambientes Virtuais de Aprendizagem em diferentes contextos. Rio de Janeiro: Editora Ciência Moderna Ltda.

Pereira, A. S., et al. (2018). Metodologia da pesquisa científica. [e-book]. Santa Maria. Ed. UAB/NTE/UFSM. Recuperado de https://repositorio.ufsm.br/bitstream/handle/1/1 5824/Lic_Computacao_Metodologia-Pesquisa-Cientifica.pdf?sequence=1.

Rochelle, J. (2016). Introducing $G$ Suite for Education. Recuperado de http://blog.go ogle/topics/education/introducing-g-suite-education/

Santos, C. (2017). O que é o G Suite for Education e como usá-lo? Recuperado de http://www.santodigital.com.br/o-que-e-o-g-suite-for-education-e-como-usa-lo/

Schiehl, E. P., \& Gasparini, I. (2016). Contribuições do Google Sala de Aula para o Ensino Híbrido. Departamento de Ciências da Computação - PPGECMT1 e PPGCA2 Universidade do Estado de Santa Catarina (UDESC). Recuperado de http://seer.ufrgs.br//index.php/renote/ article/viewFile/70684/40120 
Valente, J. A. (2014). Blended learning e as mudanças no ensino superior: a proposta da sala de aula invertida. Educar em Revista, núm. 4, 79-97. Universidade Federal do Paraná, Brasil.

Yaegashi, Solange e outros (Orgs). (2017). Novas Tecnologias Digitais: Reflexões sobre mediação, aprendizagem e desenvolvimento. Curitiba: CRV.

\title{
Porcentagem de contribuição de cada autor no manuscrito
}

\author{
Douglas dos Santos Silva - 70\% \\ Leane Amaral Paz Andrade - 20\% \\ Silvana Maria Pantoja dos Santos $-10 \%$
}

